\title{
The Influence of Fiber on the Resistance to Chloride-Ion Penetration of Concrete under the Environment of Carbonation
}

\author{
Qi HUANG ${ }^{1, a}$, Xiao-Shuang SHI ${ }^{1, b^{*}}$, Qing-Yuan WANG ${ }^{1,2, c}$, Ling TANG ${ }^{1, d}$, \\ Hong-En ZHANG ${ }^{1, \mathrm{e}}$
}

\author{
${ }^{1}$ College of Architecture and Environment, Sichuan University, Sichuan Chengdu 610065 \\ ${ }^{2}$ Advanced Research Institute, Chengdu University, Sichuan Chengdu 610065 \\ ahuangqiscu@foxmail.com, bshixs@scu.edu.cn, cwangqy@scu.edu.cn, dtanglinghnuscu@163.com, \\ escuhongenzhang@163.com
}

${ }^{*}$ Corresponding author

Keywords: Fiber, Carbonization, Porosity, Chloride-ion Penetration, SEM.

\begin{abstract}
The rapid chloride penetrating test of ordinary Portland concrete (OPC), glass fiber reinforced concrete (GFRC) and basalt fiber reinforced concrete (BFRC) were carried out under the environment of carbonation. This study investigates the differences of carbonization depth, porosity and permeability with the increase of carbonation ages by comparing the effect of fiber on chloride penetration resistance of concrete, and observing the microstructure through scanning electron microscope (SEM). The results show that glass and basalt fiber increases the porosity of concrete, but the carbonization depth at the beginning of carbonation was reduced, so as to improve carbonation resistance. Carbonation resistance of basalt reinforced concrete is better. Carbonation reaction would enhance the resistance to chloride ion penetration of concrete, which glass fiber performs better than basalt fiber does.
\end{abstract}

\section{Introduction}

Concrete is a kind of brittle material with a low tensile strength and strain limit. Nowadays, fibers have been successfully used in concrete to improve its engineering properties such as the tensile, flexural, impact, toughness, and limit the crack width, with beneficial consequences in terms of concrete durability[1-3]. Since durability is a major topic in concrete structure nowadays, and considering that the use of fiber is progressively growing in the field of structure elements, there is now an increasing need of better understanding of fiber reinforced concrete behavior in response to environmental actions.

The corrosion has a detrimental effect on the durability of reinforced concrete structure. The primary causes of corrosion are chloride-penetration, and the reduction of $\mathrm{pH}$ of the concrete matrix due to carbonation. The paper investigates the effect of two kinds of fiber: glass fiber and basalt fiber on the resistance to the chloride-ion penetration of concrete under the environment of carbonation. Both of basalt fiber and glass fiber have high elastic modulus and stiffness and thus the addition of these two kinds of fibers are effective for improving the compressive strength and toughness of concrete. Besides, both of them have high modulus, heat resistance to chemical attack and so on. Basalt fiber is a kind of inorganic fiber extruded from melted basalt rock. The manufacturing process of basalt fiber is similar to that of glass fiber, but basalt fiber is cheaper than glass fiber because of less energy consumed and no additives[4-5]. In general, basalt fiber is a good alternative to glass fiber, but which one have better influence on the durability of concrete deserves study further.

\section{Experimental Procedures}

\section{Material}

Ordinary Portland cement (Class 42.5R), river sand (as fine aggregate with a fineness modulus of 2.8 ), crushed stone with a maximum nominal size of $22 \mathrm{~mm}$ was used as the coarse aggregae,and 
potable water was used in this work. The physical properties of basalt fiber and glass fiber were summarized in Table 1 and Table 2, respectively.

Tab. 1 Physical properties of basalt fiber

\begin{tabular}{cccc}
\hline Tensile strength $(\mathrm{MPa})$ & Breaking elongation $(\%)$ & Elasticity modulus $\left(\mathrm{kg} / \mathrm{m}^{2}\right)$ & Coefficient of heat conduction $(\omega / \mathrm{m} \cdot \mathrm{k})$ \\
\hline 2250 & 3.5 & 10500 & 0.035 \\
\hline
\end{tabular}

Tab. 2 Physical properties of glass fiber

\begin{tabular}{cccccc}
\hline $\begin{array}{c}\text { Diameter } \\
(\mu \mathrm{m})\end{array}$ & $\begin{array}{c}\text { Specific weight } \\
\left(\mathrm{g} / \mathrm{cm}^{3}\right)\end{array}$ & $\begin{array}{c}\text { Tensile strength } \\
(\mathrm{MPa})\end{array}$ & $\begin{array}{c}\text { Volume } \\
\text { resistivity }(\Omega \cdot \mathrm{cm})\end{array}$ & $\begin{array}{c}\text { Breaking elongation } \\
(\%)\end{array}$ & $\begin{array}{c}\text { Specific heat } \\
(\mathrm{kca} / \mathrm{kg} \cdot \mathrm{degree})\end{array}$ \\
\hline 14 & 2.6 & $\geq 630$ & 105 & 3.5 & 0.19 \\
\hline
\end{tabular}

Test Methods

In the process of the preparation of fiber reinforced concrete, these steps need to be followed in order to avoid uneven distribution and destroy in fibers: firstly, blended cement made with rushed stone, sand and fiber for about $1 \mathrm{~min}$, and then blended for $3 \mathrm{mins}$ with addition of water; secondly, concrete composite should be putted in the cylinder and prisms molds, such as $\Phi 100 \mathrm{~mm} \times 200 \mathrm{~mm}$ and $100 \times 100 \times 400 \mathrm{~mm}$, the cylinders were casted in two layers, with each layer being consolidated on a vibration table; finally, all the molded specimens were covered with plastic sheets and water-saturated burlap and placed in room for $24 \mathrm{~h}$, and then transferred to a standard curing chamber for concrete after demolded. The mixture proportion of concrete in this paper was summarized in Table 3.

Tab. 3 Mixture proportion of concrete

\begin{tabular}{lcccccc}
\hline Number & $\begin{array}{c}\text { Cement content } \\
\left(\mathrm{kg} / \mathrm{m}^{3}\right)\end{array}$ & $\begin{array}{c}\text { Coarse aggregate } \\
\left(\mathrm{kg} / \mathrm{m}^{3}\right)\end{array}$ & $\begin{array}{c}\text { Fine aggregate } \\
\left(\mathrm{kg} / \mathrm{m}^{3}\right)\end{array}$ & $\begin{array}{c}\text { Water } \\
\left(\mathrm{kg} / \mathrm{m}^{3}\right)\end{array}$ & $\begin{array}{c}\text { Glass fiber } \\
\left(\mathrm{kg} / \mathrm{m}^{3}\right)\end{array}$ & $\begin{array}{c}\text { Basalt fiber } \\
\left(\mathrm{kg} / \mathrm{m}^{3}\right)\end{array}$ \\
\hline OPC & 437 & 1318 & 647 & 218 & - & - \\
GFRC & 437 & 1318 & 647 & 218 & 2 & - \\
BGRC & 437 & 1318 & 647 & 218 & - & 2 \\
\hline
\end{tabular}

\section{Results and Discussion}

\section{The Influence of Fiber on the Carbonation Resistance Performance of Concrete}

A series of prisms specimens with the size of $100 \times 100 \times 400 \mathrm{~mm}$ were used to determine the carbonation resistance of concrete composite. The carbonation resistance of concrete composite can be evaluated by carbonation depth of the specimen under the action of $\mathrm{CO}_{2}$ pressure. Before testing, the specimens were cured for 28 days at $90 \%$ relative humidity and controlled temperature $(20 \pm 2)^{\circ} \mathrm{C}$. The test of concrete carbonation was carried out in concrete box in accordance with Chinese Standard. In the concrete carbonation box, the $\mathrm{CO}_{2}$ concentration should be controlled at $20 \pm 2 \%$, and the humidity and temperature should be controlled at $70 \pm 2 \%$ and $20 \pm 2{ }^{\circ} \mathrm{C}$, respectively. The carbonation test has lasted for 42 days. After the test finished, the specimen was cut down for about $5 \mathrm{~mm}$, the fracture surface of the small part was spayed phenolphthalein alcohol solution with the level of $1 \%$. Finally, the average carbonation depth can be measured.

The results about the influence of these two kinds of fiber on the carbonation depth were shown in Figure 1. The shorter carbonation depth indicates that the concrete composites has better carbonation resistance. As can be seen from the relation curve, on the third day of carbonization, basalt fiber and glass fiber can reduce the carbonation depth greatly, the carbonization depth of basalt fiber and glass fiber reinforced concrete were decreased by $41 \%$ and $23 \%$ compared with ordinary concrete, respectively. The presence of fiber in concrete reduces the carbonation depth considerably in initial 
stage of carbonation. The carbonation resistance of glass fiber is decreasing gradually with the increase of carbonation ages, but basalt fiber reinforced concrete keeps good carbonation resistance performance.

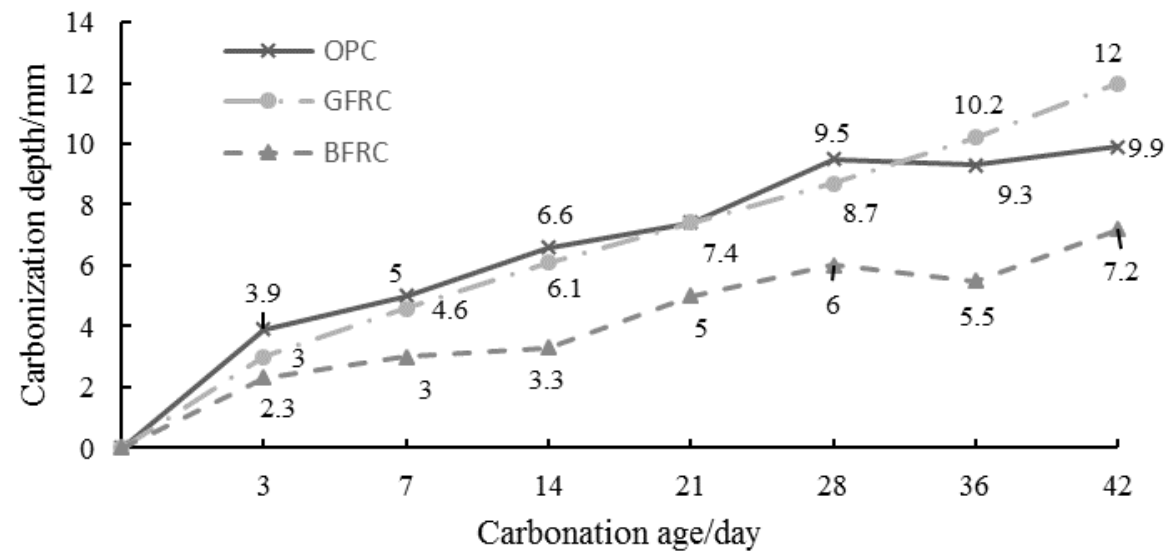

Fig.1 Carbonization depth with increasing carbonation ages

\section{The Influence of Fiber on the Porosity and Permeability of Concrete}

The porosity and permeability of concrete were tested by MicroMR12-025V in NIUMAG COMPANY in Shanghai. The specimens were under vacuum saturated state for $24 \mathrm{~h}$, and then were tested by low field proton nuclear magnetic resonance (NMR) technology. The results of the test are shown in Table 4.

Tab.4 Porosity and permeability of concrete

\begin{tabular}{l|ccc|ccc}
\hline & \multicolumn{3}{|c|}{$\begin{array}{c}\text { Porosity (\%) } \\
\text { After }\end{array}$} & \multicolumn{3}{c}{ Permeability (md) } \\
Number & $\begin{array}{c}\text { Before } \\
\text { carbonation(1) }\end{array}$ & $\begin{array}{c}\text { carbonation(2) } \\
\text { cafter }\end{array}$ & $\begin{array}{c}\text { (2)-(1) }) /(1) \\
\text { carbonation(3) }\end{array}$ & $\begin{array}{c}\text { carbonation(4) } \\
\text { (4)-(3))/(3) }\end{array}$ \\
\hline OPC & $5.13 \%$ & $12.41 \%$ & $141.9 \%$ & 0.43 & 0.31 & $-27.90 \%$ \\
GFRC & $7.65 \%$ & $11.59 \%$ & $51.5 \%$ & 2.69 & 0.39 & $-85.50 \%$ \\
BGRC & $7.72 \%$ & $5.57 \%$ & $-27.8 \%$ & 3.26 & 0.01 & $-99.70 \%$ \\
\hline
\end{tabular}

It can be seen from the figures that compared with OPC, the porosity of GFRC increased $49.1 \%$, the porosity of BFRC increased $50.5 \%$. This is because that the air was entrained with the addition of fibers, and it changed the air content in the concrete. It concluded that the addition of fibers can increase the porosity[6], namely, the measured porosity of GFRC and BFRC is higher than that of OPC and attributed this difference to the interfacial porosity.

After carbonation for 28 days, the porosity of GFRC increased $51.5 \%$ than its initial value; the porosity of BFRC decreased $27.8 \%$ than its initial value; the porosity of both of these two kinds of fiber reinforced concretes were lower than that of OPC. Compared with OPC, the permeability of GFRC increased $525.6 \%$, the permeability of BFRC increased $658.1 \%$. It concluded that the addition of fibers can increase the permeability which is bad for the chloride penetration resistance of concrete. After carbonation for 28 days, the permeability of GFRC decreased $85.5 \%$ than its initial value; the porosity of BFRC decreased $99.7 \%$ than its initial value; the permeability of BFRC was lower than OPC, and the permeability of GFRC was a little bit higher than OPC.

This is a clear evidence that accelerated carbonation improves the contact between fibers and cement matrix, and fibers improved the chloride penetration resistance of concrete under the environment of acceleration carbonation[7]. The chloride penetration resistance of BFRC is better than that of GFRC. Through $\mathrm{CO}_{2}$ 's reaction with hydration products of hydration products of Portland cement formed $\mathrm{CaCO}_{3}$, and $\mathrm{CaCO}_{3}$ is precipitated in the pore structure of the matrix refining the pore distribution, but carbonation results in coarsening pore structure at the same time, the effect 
of the latter is more obvious.

\section{The Influence of Fiber on the Resistance to the Chloride-ion Penetration of Concrete}

The concrete mixtures were prepared in the laboratory using a pan mixer. Cylinders of $100 \mathrm{~mm}$ in diameter and $200 \mathrm{~mm}$ in height were cast in steel mould and compacted on a vibrating table. From each concrete cylinder, two $50 \mathrm{~mm}$ thick section were obtained for these tests using a diamond saw. The resistance to the chloride-ion penetration of GFRC and BFRC was determined following the procedures of ASTM C1202 using the 50mm thick portions as sample from the 100 by $200 \mathrm{~mm}$ concrete cylinders at 7,14,21,28 days. The resistance of concrete against chloride-ion penetration is expressed as an electrical indication: the total charge passed in coulombs during a test period of $6 \mathrm{~h}$.

Table 6 presents data on the resistance of the concrete to chloride-ion penetration. The results show that the use of glass fiber and basalt fiber decrease the resistance to the chloride-ion penetration of concrete. The decrease in resistance was due primarily to the addition of fibers that increase the air content and resulted in a high porosity microstructure of the paste in concrete compared to that of OPC made without fibers[8], namely the addition of fiber decreases the resistance to chloride-ion penetration and the resistance of BFRC is lower than that of GFRC.

Tab. 5 ASTMC 1202 the permeability of concrete

\begin{tabular}{rr}
\hline Quantity of electricity/C & Chloride-ion penetration \\
\hline$>4000$ & high \\
$2000-4000$ & medium \\
$1000-2000$ & low \\
$100-1000$ & very low \\
$<100$ & impermeable \\
\hline
\end{tabular}

Tab. 6 Chloride-ion penetration of concrete

\begin{tabular}{ccc}
\hline Number & $\begin{array}{c}\text { Quantity of } \\
\text { electricity/C }\end{array}$ & $\begin{array}{c}\text { Chloride-ion } \\
\text { penetration }\end{array}$ \\
\hline OPC & 1874.8 & low \\
GFRC & 1900.1 & low \\
BGRC & 2121.9 & medium \\
\hline
\end{tabular}

The Influence of Fiber on the Resistance to Chloride-ion Penetration of Concrete under the Environment of Carbonation

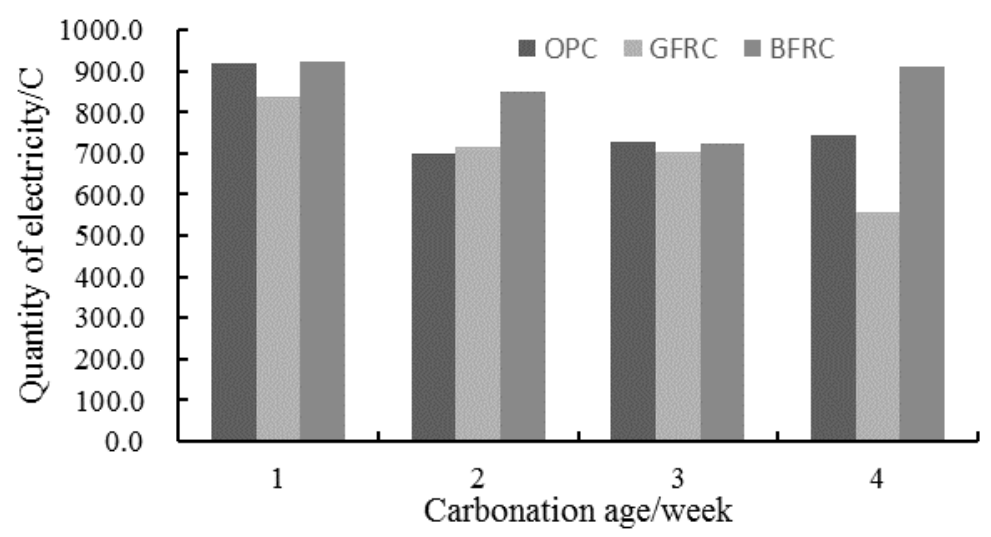

Fig. 2 Quantity of electricity with increasing carbonation age

Figure 2 shows that the quantity of electricity of OPC decreases with increasing carbonation ages, namely carbonation reaction improves the resistance to chloride-ion penetration. The trend of 
GFRC is similar to OPC, but the ultimate quantity of electricity of GFRC is lower, and the addition of glass fiber can enhance the resistance to chloride-ion penetration in accelerated carbonation effectively. The quantity of electricity of BFRC decreases in first three weeks of carbonation ages, but increases suddenly in the fourth week, which means the resistance to chloride-ion penetration decreases because of the addition of basalt fiber.

Different kinds of fiber have different influence on the resistance to chloride-ion penetration of concrete in accelerated carbonation: glass fiber improve the resistance, but basalt fiber decreases.

\section{The Microstructure of Fiber Reinforced Concrete}

The microstructure of basalt fiber and glass fiber reinforced concrete were observed by HITACHI S-4800 scanning electron microscopy (SEM) in Research Center of Biological Materials Engineering in Sichuan University to learn more about the effect of these two kinds of fiber on the internal structure, and to infer influence on the durability of concrete. SEM is an effective way to investigate the morphology of hydrated cement-based products. The microstructures of different concrete are shown in Figure 3.

It was found that obvious fibrous materials were filled in the micro pores of cement. A large number of fibers formed network structure, so that connected tunnels were avoided. The incorporation of basalt fiber and glass fiber in the cement pastes resulted in a finer pore size distribution compared with the OPC pastes[9].

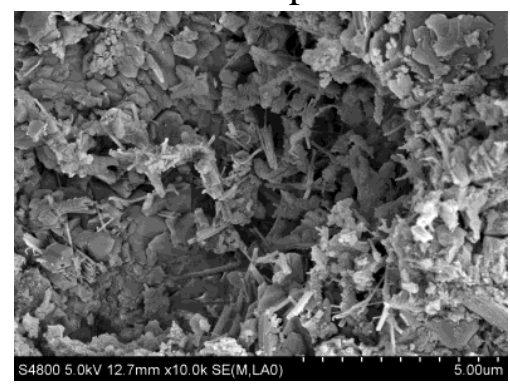

(a) OPC

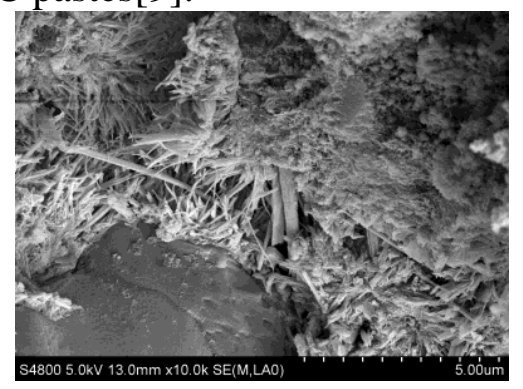

(b) GFRC

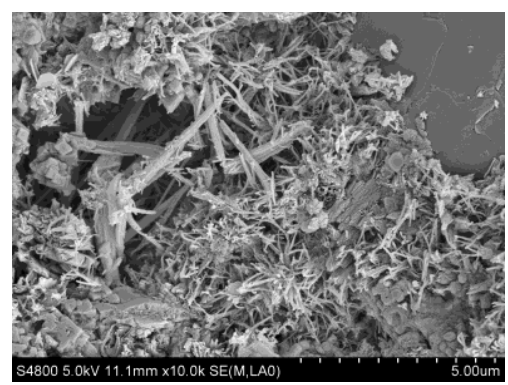

(c) BFRC

Fig. 3 SEM photos of fiber reinforced concrete

\section{Conclusion}

1. The addition of glass fiber and basalt fiber can reduce the carbonization depth, and improve the carbonation resistance. Basalt fiber is more effective and is not influenced by carbonation ages.

2. Accelerated carbonation improves the contact between fibers and cement matrix, and coarsen the pores in cement. The influence of coarsening on porosity and permeability is more obviously.

3. The use of glass and basalt fiber decrease the resistance to the chloride-ion penetration of concrete. Glass fiber improves the resistance to chloride-ion penetration of concrete in accelerated carbonation, but basalt fiber performs a contrary result.

4. The incorporation of basalt fiber and glass fiber in the cement pastes resulted in a finer pore size distribution compared with the OPC pastes.

\section{Acknowledgements}

This investigation was financially supported by the National Natural Science Foundation of China (51208325), Ministry of Education Key laboratory of Energy Engineering and Disaster Mechanics.

\section{References}

[1] Tassew ST, Lubell AS. Mechanical properties of glass fibre reinforced ceramic concrete. 
Construct Build Mater2014; 51: 215-24.

[2] Faiz UAS. Review of mechanical properties of short fibre reinforced geoploymer composites. Construct Build Mater 2013; 43: 37-49.

[3] Bischoff P. Tension stiffening and cracking of steel fiber-reinforced concrete. J Mater Civ Eng 2003; 15(2):174-82.

[4] Lopresto V, Leone C, De lorio I. Mechanical properties of basalt fibre reinforced plastic. Compos B Eng 2011; 42(4): 717-23.

[5] Borhan TM. Properties of glass concrete reinforced with short basalt fibre. Mater Des 2012; 42; 265-71.

[6] Chaohua Jiang, Ke Fan, Fei Wu et al. Experimental study on the mechanical properties and microstructure of chopped basalt fiber reinforced concrete, Materials and Design 2014(58):187-193.

[7] C.S.Poon, S.C.Kou, L.Lam, Compressive strength, chloride diffusivity and pore structure of high performance metakaolin and silica fume concrete. Construction and Building Materials.2006; 20: 858-65.

[8] T.A.SÖylev T. Özturan. Durability, physical and mechanical properties of fiber-reinforced concrete at low-volume fraction. Construction and Building Materials, 2014; 73:67-75.

[9] V.D.Pizzol, L.M.Mendes, H.Savastano Jr et al. Mineralogical and microstructure change promoted by accelerated carbonation and ageing cycles of hybrid fiber-cement composites, Construction and Building Materials, 2014(68): 750-756. 